\section{Paracoccidioidomycosis mortality in the State of Paraná, Brazil, 1980/1998}

\author{
Mortalidade por paracoccidiodomicose \\ no Estado do Paraná, Brasil, 1980/1998
}

\author{
1 Universidade Estadual \\ de Ponta Grossa, \\ Ponta Grossa, Brasil. \\ 2 Escola Nacional de Saúde \\ Pública Sergio Arouca, \\ Fundação Oswaldo Cruz, \\ Rio de Janeiro, Brasil. \\ Correspondência \\ R. M. Oliveira \\ Departamento de Endemias \\ Samuel Pessoa, Escola \\ Nacional de Saúde Pública \\ Sergio Arouca, Fundação \\ Oswaldo Cruz. \\ Rua Leopoldo Bulhões 1480, \\ Rio de Janeiro, $R J$ \\ 210410-210, Brasil. \\ rosely@ensp.fiocruz.br
}

\section{Abstract}

The paracoccidioidomycosis mortality rate in the State of Paraná, Brazil (1980/1998) was analyzed using the death registry data from the Brazilian Mortality Information System and the estimated population from the Brazilian Institute of Geography and Statistics. To qualify the deaths, we deployed ICD-9 for 1980/1995 and ICD-10 for the more recent years. During this period there were 551 deaths from paracoccidioidomycosis in the State of Paraná. Most of the deaths were in male in the 30-59-year age group. The average annual mortality rate was 3.48 per million inhabitants, showing a tendency to stabilize during the study period. Paracoccidioidomycosis was the fifth cause of mortality among the predominantly chronic infectious diseases and had the highest mortality rate among the systemic mycoses. Paracoccidioidomycosis was observed in 184 counties in the State of Paraná. Most deaths were recorded in the North-Central meso-region, and the highest mortality rate occurred in the West meso-region.

Paracoccidioidomycosis; Mortality; Mycosis
Jeanine Izabel Margraf Bittencourt 1

Rosely Magalhães de Oliveira ${ }^{2}$

Ziadir Francisco Coutinho ${ }^{2}$

\section{Introduction}

Paracoccidioidomycosis is a systemic mycosis, with a geographic distribution limited to the Americas, specifically the Latin American countries, and whose etiological agent is the dimorphic fungus Paracoccidioides brasiliensis 1 .

The disease is characterized by a primary lung infection, frequently unapparent, which can disseminate, principally presenting lesions on the mucosae of the upper airways and upper digestive tract and occasionally the gastrointestinal tract. The lymph nodes are frequently involved and occasionally the disease extends to other organs, especially the skin tissue and adrenal glands 2,3.

The clinical manifestations of paracoccidioidomycosis require a differential diagnosis with various diseases, particularly tuberculosis (coexisting in 10.0 to $25.0 \%$ of cases), histoplasmosis, sarcoidosis, coccidioidomycosis, Hansen disease, and lymphomas.

The importance of the disease in public health is linked to its high social and economic costs, since it occurs in individuals in the most productive stage of life, causing frequent sequelae, a common cause of work disability 4 .

Although the disease continues to pose a serious social problem, it impossible to establish its true distribution because it is not a disease of mandatory reporting. In addition, the lack of more consistent knowledge on the etio- 
logical agent's ecology and the epidemiology of the mycosis hinder the implementation of adequate preventive measures 5 .

According to estimates, some 10 million individuals are infected with the fungus, $2.0 \%$ of whom may develop the disease 6 . In Brazil, estimates indicate an annual incidence of 1 to 3 cases per 100 thousand inhabitants in areas with high endemicity, with a mortality coefficient of 0.14 per 100 thousand inhabitants 7 .

According to a study on paracoccidioidomycosis mortality in Brazil from 1980 to 1995, the disease was the eighth cause of mortality among the predominantly infectious and parasitic diseases, and Paraná had the highest rate among all States in the South and Southeast regions of Brazil, with $14.5 \%$ of the deaths from the disease in Brazil, showing a mean annual mortality coefficient of $3.52 /$ million inhabitants 8,9 .

Due to the high rates found in the State of Paraná and the scarcity of studies aimed at control of the disease, the current study proposed to analyze paracoccidioidomycosis mortality in the State of Paraná, considering epidemiological, socioeconomic, climatic, and soil factors in the various regions of the State.

\section{Material and methods}

Data on the number of deaths from paracoccidioidomycosis from 1980 to 1998 were taken from the CD-ROM of the Mortality Information System furnished by the Departamento de Informática do SUS - DATASUS (Information Technology Department of the Unified National Health System), version September 2000.

The basic cause of death was classified according to the 9th International Classification of Diseases (ICD-9) for 1980/1995 and the 10th International Classification of Diseases (ICD10) for 1996/1998.

The estimated data for the same period on the resident populations in the State of Paraná, South, and Southeast of Brazil were taken from the DATASUS website (http://www.datasus. gov.br), which used the total population estimate and the estimate by municipality (county) calculated and provided by the Brazilian Institute of Geography and Statistics (IBGE).

The death certificates for paracoccidioidomycosis from 1996 to 1998 were obtained from the files of the Secretaria de Estado da Saúde do Paraná - SES-PR (Paraná State Health Secretariat).
Information on the characterization of the geographic area was obtained from websites of the Instituto Paranaense de Desenvolvimento Econômico e Social (Paraná State Institute for Development) (http://www.ipardes.gov.br), Governo do Estado do Paraná (Paraná State Government) (http://www.pr.gov.br), and the IBGE (http://www.ibge.gov.br).

Deaths were searched and added, using for 1980-1995 the codes referring to blastomycotic infection: (116.0) - blastomycosis and (116.1) paracoccidioidomycosis, which are part of ICD9, and codes (B 40) - blastomycosis and (B 41) paracoccidioidomycosis, part of ICD-10, for 1996/1998.

The data obtained from the CD-ROM were transported to Excel, where the mortality coefficients were calculated and the graphs were prepared.

Using the same procedure, deaths were searched and mortality coefficients were calculated for the most important predominantly chronic infectious diseases in the State, with the objective of comparing and situating paracoccidioidomycosis mortality.

The Tabwin program was used for elaboration of maps.

The variables selected for the study were: gender, age, occupation, and place of residence, obtained from the Mortality Information System database.

In order to identify possible associations with environmental variables, data were collected on rainfall, altitude, temperature, and predominant farm crops for the different mesoregions in the State.

Occupations were analyzed according to participation in the labor market, separating the less clearly defined categories (retired, unemployed, students, housewives, and unknown) from those established and defined as active in the workforce according to the categories used in the IBGE censuses.

Copies were also made of 89 death certificates with paracoccidioidomycosis as cause of death in the years 1996, 1997, and 1998, from the SES-PR files, for exploratory data analysis, identifying possible recording problems.

\section{Results and discussion}

The State of Paraná showed a mean annual mortality coefficient from paracoccidioidomycosis of 3.48 per million inhabitants for the pe- 
Paracoccidioidomycosis deaths and mortality coefficients in the States of Southeast and South Brazil, 1980/1998.

\begin{tabular}{lcccc}
\hline States & Total deaths & Mean deaths & Mean population & Coefficient \\
\hline Espírito Santo & 124 & 6.53 & $2,481,009$ & 2.63 \\
Minas Gerais & 465 & 24.47 & $15,274,190$ & 1.60 \\
Rio de Janeiro & 281 & 14.79 & $12,507,469$ & 1.18 \\
São Paulo & 1,099 & 57.84 & $30,281,218$ & 1.91 \\
Total, Southeast & 1,969 & 103.63 & $60,543,886$ & 1.71 \\
Paraná & 551 & 29.00 & $8,333,876$ & 3.48 \\
Rio Grande do Sul & 316 & 16.63 & $8,860,085$ & 1.88 \\
Santa Catarina & 154 & 8.10 & $4,355,337$ & 1.86 \\
Total, South & 1,021 & 53.74 & $21,549,320$ & 2.49 \\
\hline
\end{tabular}

Source: Departamento de Informática do SUS (Information Technology Department, Unified National Health System). http://www.datasus.gov.br (accessed on 20/Dec/2001); Instituto Brasileiro de Geografia e Estatística (Brazilian Institute of Geography and Statistics). http://www.sidra.ibge.gov.br (accessed on 25/Jan/2002).

Note: mortality coefficient per 1 million inhabitants.

riod from 1980 to 1998 (Table 1). This result is consistent with the value obtained in a study on mycosis mortality in Brazil, showing a State coefficient of 3.52 per million inhabitants for the period from 1980 to 1995 , representing the highest rate among the States from the Southeast and South of Brazil 8,9.

Brazil showed 3,693 paracoccidioidomycosis deaths in the historical series from 1980 to 1998 , with $27.6 \%$ of these deaths $(1,021)$ in the South. As described in the literature, the majority of the cases were reported in the South, Southeast, and Central-West 10.

During the same period, the State of Paraná presented 551 deaths from this mycosis, with an annual mean of 29 deaths. The disease accounted for 316 deaths in the State of Rio Grande do Sul and 154 in the State of Santa Catarina. These findings thus mean that Paraná occupies first place in the number of paracoccidioidomycosis deaths among the States comprising the South of Brazil, correlating with the values obtained in a study on paracoccidioidomycosis mortality in Brazil from 1980 to 1995 8,9.

Among the Brazilian States with the most deaths from paracoccidioidomycosis, Paraná is in second place, next only to the State of São Paulo, with 1,099 deaths in the historical series studied, reaffirming the higher occurrence of paracoccidioidomycosis in the South and Southeast regions of the country.

Paracoccidioidomycosis mortality in the State of Paraná showed a wide variation in relation to age. The youngest age with a recorded death was five years and the oldest was 84 years. The literature reports cases of the disease from 3 to 102 years of age 11,12 .
The distribution of paracoccidioidomycosis deaths in the age bracket greater than 15 years was $98.9 \%$, as compared to $1.1 \%$ in individuals under 15 years. These data are consistent with a study on mortality in Brazil for the period $1980 / 1995$, for these same age brackets, showing $95.9 \%$ of the deaths in individuals greater than 15 years of age 8,9 .

Further analyzing the distribution of deaths from paracoccidioidomycosis according to age group (Table 2), in the under-15-year bracket the deaths occurred in equal proportions between the two genders, while in the over-15year group men accounted for $85.3 \%$ of the deaths as compared to $14.7 \%$ in women. These findings corroborate the literature, according to which the infection and disease occur equally between the genders during childhood, with a slight predominance of males with the disease, as compared to an absolute predominance of males among adults with the chronic form of the mycosis 13 .

The highest number of deaths was observed in the 50-59-year group, coinciding with a clinical study in the State of Rio Grande do Sul, reviewing the medical histories of 260 paracoccidioidomycosis patients observed from 1958 to 1987 , in which the majority of the cases occurred in this age bracket 12 .

Males accounted for $85.0 \%$ of the deaths and showed a mean annual mortality coefficient of 5.91 per million inhabitants, reaffirming the constant repetition since the initial observations concerning the epidemiological aspects of paracoccidioidomycosis, highlighting the predominance of disease cases in males 12,14. The explanations for this fact are based on 
the notions that: (1) men have more routine and daily contact with sources of the infection; (2) men are more heavily involved in rural labor; and (3) hormonal factors play a protective role in women, possibly due to estrogen activity, acting to enhance the cellular immune response 15 .

Of the total deaths in men, $4.4 \%$ occurred up to 29 years of age as compared to $65.1 \%$ from 30 to 59 years. These data agree with morbidity studies concerning the higher incidence in males 30 to 60 years of age, contrary to the observation for paracoccidioidomycosis-infection, which is more frequent in younger age brackets. One of the explanations for this difference in age-related prevalence between paracoccidioidomycosis-infection and paracoccidioidomycosis-disease is the reactivation of a quiescent lesion many years after infection 16.

In relation to individuals' occupation at time of death, $37.2 \%$ (205) were either not in the formal labor market, retired, or had occupation unknown. Individuals with well-defined occupations accounted for $62.8 \%$ of the total (346). Of these, $67.9 \%$ of the deaths occurred in rural workers, followed by construction workers (with $14.1 \%$ of the deaths).

Agricultural activity, as the profession in the majority of the individuals who acquired and died of paracoccidioidomycosis in the current study, coincides with data from other morbidity studies 14,15,17.

The discussion on the reasons for the high incidence in bricklayers can take two approaches. The first is based on the premise that bricklayers comprise a community formed mainly of migrants from the countryside, that is, former farm workers who were infected over the course of their previous profession.

Another possibility is that infection occurs in the urban area itself, to the extent that construction work involves handling earth and wood 14 . This analysis emphasizes the need to investigate the patient's lifetime "history" when one studies the epidemiology of paracoccidioidomycosis.

Death records from paracoccidioidomycosis were found in 184 municipalities (counties) in the State, corresponding to $46.1 \%$ of the total of 399 municipalities in Paraná. The municipalities with the most cases were Curitiba, Londrina, Toledo, Cascavel, Ponta Grossa, and Prudentópolis.

Borelli 18 (p. 72) created the concept of de "reservárea" (or reservoir area) to define "the places where factors exist and act to condition infection", that is, areas in which individuals become infected. Identification of such areas is
Table 2

Percentage distribution of paracoccidioidomycosis deaths according to age bracket and gender. Paraná State, Brazil, 1980/1998.

\begin{tabular}{lrrrrrr}
\hline \multirow{2}{*}{ Age brackets } & \multicolumn{2}{c}{ Male } & \multicolumn{2}{c}{ Female } & \multicolumn{2}{c}{ Total } \\
& Deaths & $\%$ & Deaths & $\%$ & Deaths & $\%$ \\
\hline $5-9$ & 2 & 50.00 & 2 & 50.00 & 4 & 100.00 \\
$10-14$ & 1 & 50.00 & 1 & 50.00 & 2 & 100.00 \\
$15-19$ & 2 & 50.00 & 2 & 50.00 & 4 & 100.00 \\
$20-29$ & 16 & 80.00 & 4 & 20.00 & 20 & 100.00 \\
$30-39$ & 47 & 77.05 & 14 & 22.95 & 61 & 100.00 \\
$40-49$ & 108 & 87.10 & 16 & 12.90 & 124 & 100.00 \\
$50-59$ & 150 & 89.30 & 18 & 10.70 & 168 & 100.00 \\
$60-69$ & 81 & 83.50 & 16 & 16.50 & 97 & 100.00 \\
$70-79$ & 49 & 86.00 & 8 & 14.00 & 57 & 100.00 \\
80 and + & 12 & 85.70 & 2 & 14.30 & 14 & 100.00 \\
Total & 468 & 85.00 & 83 & 15.00 & 551 & 100.00
\end{tabular}

Source: Departamento de Informática do SUS (Information Technology Department, Unified National Health System). http://www.datasus.gov.br (accessed on 20/Dec/2001).

important in the attempts to isolate the fungus from the soil, demarcation of ecological niches, and the search for possible animal reservoirs or vectors. In addition, these areas are believed to be characterized by factors limited to the ecosystem, such as altitude, temperature, rainfall pattern, soil characteristics, and vegetation 15.

The municipalities of Curitiba, Ponta Grossa, and Prudentópolis have a mesothermal humid subtropical climate, mild summers (mean temperature less than $22^{\circ} \mathrm{C}$ ), winters with severe and frequent frosts (mean temperature less than $18^{\circ} \mathrm{C}$ ), and no dry season. The altitudes are 908,975 , and $730 \mathrm{~m}$, respectively, and mean annual rainfall is approximately $1,500 \mathrm{~mm}$.

The municipalities of Londrina, Cascavel, and Toledo have hot summers with a tendency towards concentration of rains (mean temperature greater than $22^{\circ} \mathrm{C}$ ), winters with rare frosts, and no well-defined dry season, with altitudes of 576,800 , and $547 \mathrm{~m}$, respectively, and rainfall ranging from 1,500 to $2,400 \mathrm{~mm}$ /year (http://www.paranacidade.org.br, accessed on 03/Apr/2002).

These municipalities have favorable climatic and environmental conditions for the survival of $P$. brasiliensis, which according to Restrepo 19 includes a temperature range of 17 $24^{\circ} \mathrm{C}$, rainfall of $500-2,500 \mathrm{~mm} /$ year, and altitude of 400-1,200m above sea level. Note that the parameters set by Restrepo 19 refer to Colombia, a country located at latitude slightly north of the Equator. In Brazil, the southern latitude should be considered when analyzing 
the other parameters, especially in the South of the country.

The individuals who died of paracoccidioidomycosis lived in these regions, but the disease has a long latency period, so it is necessary to investigate their "residential and occupational trajectories".

The highest mortality coefficients were observed in the West, Southeast, and Southwest meso-regions of Paraná (Table 3), areas characterized by tobacco farming. According to Calle et al. 20, the presence of tobacco fields is one of the ecological factors associated with paracoccidioidomycosis incidence, and although this kind of crop requires higher temperatures and a drier climate, it is developed in humid forest areas.

The higher reporting of deaths from paracoccidioidomycosis in the North-Central mesoregion, which includes the municipality de Londrina, may be explained by the fact that it is a region with a predominance of coffee farming. Silva-Vergara et al. 21, in the State of Minas Gerais, isolated P. brasiliensis from the soil in a coffee plantation, suggesting that this is one of the habitats of the fungus and that paracoccidioidomycosis may be acquired during farming activity in these areas.

However, these environmental characteristics are also observed in other municipalities which do not have high paracoccidioidomycosis mortality.

Another important aspect is the greater occurrence of deaths in the Curitiba meso-region, as the result of diagnostic facilities, greater interest by clinicians, and migratory processes.

Marked by intense modernization of agricultural practices and transformation of the industrial base in the sense of integrating various economic sectors under the hegemony of industrial capital, the State has undergone a series of highly significant structural changes. Production and rural labor relations have been altered, leading to the destabilization of rural subsistence conditions and the expulsion of huge population contingents previously linked to farming activities.

A significant share of these rural emigrants moves to the cities in the State of Paraná itself, in search of work and income opportunities. This has greatly expanded the State's degree of urbanization and the tendency to concentrate the population in larger cities.

Such shifts converge mainly towards the three most urbanized meso-regions in the State 22, which show the highest number of deaths from paracoccidioidomycosis: the Metropolitan meso-region, the North-Central meso-region, and Western Paraná, which also presented the highest mortality coefficients from the disease (Figure 1).

Although the name "paracoccidioidomycosis" was officially adopted for the disease by the International Symposium on Paracoccidioidomycosis (Medellin, Colombia, 1971), the medical community is still somewhat reluctant to use the term in daily practice 23 . As observed in the current study, $56.2 \%$ of the deaths were

Table 3

Distribution of paracoccidioidomycosis deaths and mortality coefficients by meso-region in the State of Paraná, Brazil, 1980/1998.

\begin{tabular}{lcccc}
\hline Meso-regions & Total deaths & Mean deaths & Mean population & Coefficient \\
\hline Northwest & 55 & 2.89 & $677,780.2$ & 4.27 \\
Central-West & 24 & 1.26 & 389,642 & 3.24 \\
North-Central & 102 & 5.37 & $1,611,183$ & 3.33 \\
North Pioneering & 46 & 2.42 & $557,914.1$ & 4.34 \\
Central-East & 38 & 2.00 & $534,398.1$ & 3.74 \\
West & 90 & 4.74 & $1,014,293$ & 4.67 \\
Southwest & 42 & 2.21 & $490,422.5$ & 4.51 \\
Central-South & 23 & 1.21 & $494,672.5$ & 3.48 \\
Southeast & 30 & 1.58 & $338,964.1$ & $2,224,629$
\end{tabular}

Source: Departamento de Informática do SUS (Information Technology Department, Unified National Health System). http://www.datasus.gov.br (accessed on 20/Dec/2001); Instituto Brasileiro de Geografia e Estatística

(Brazilian Institute of Geography and Statistics). http://www.sidra.ibge.gov.br (accessed on 25/Jan/2002).

Note: mortality coefficient per 1 million inhabitants. 

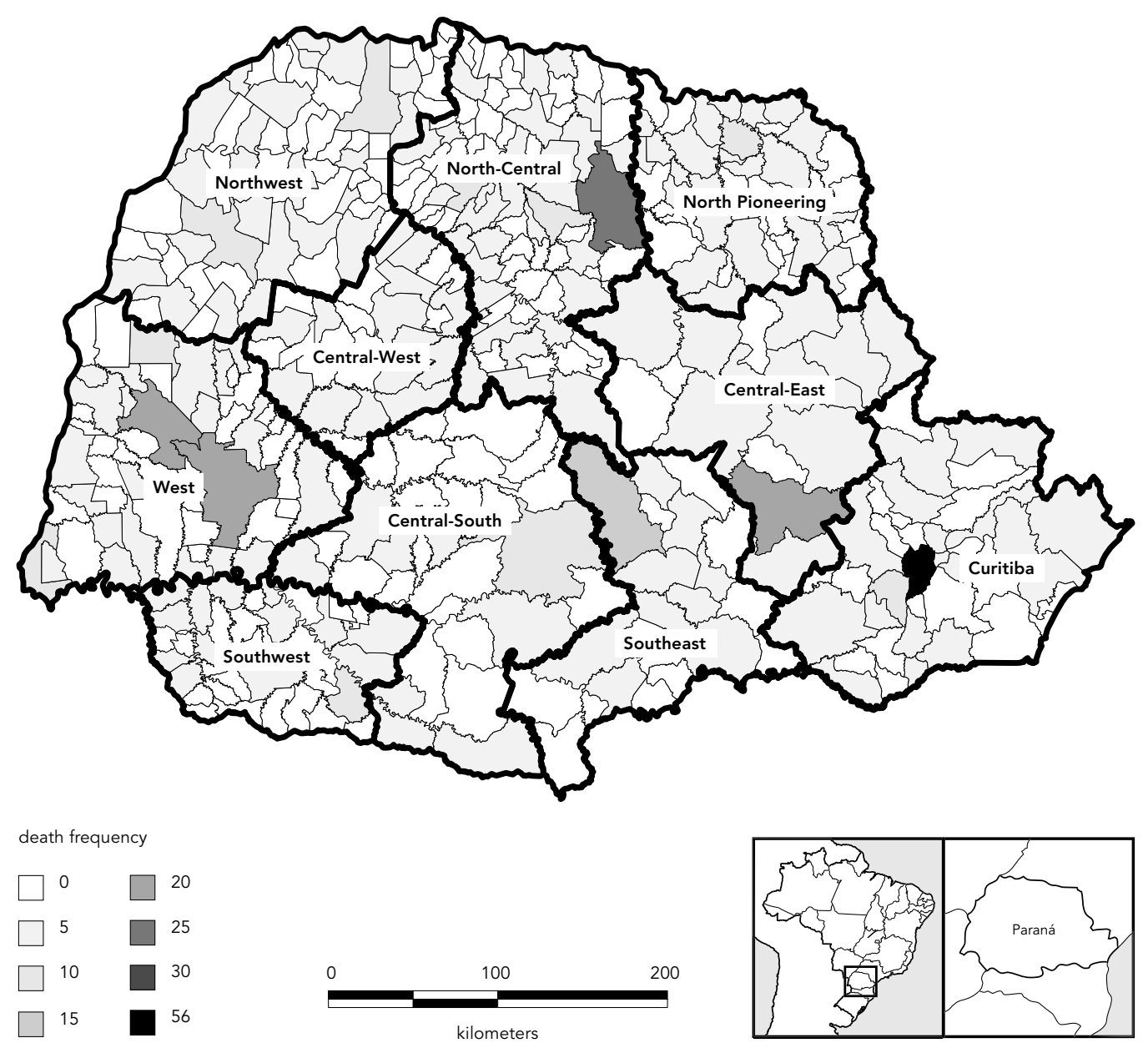

Source: Departamento de Informática do SUS (Information Technology Department, Unified National Health System) http://www.datasus.gov.br (accessed on 20/Dec/2001).

classified under the term blastomycosis, which can lead to inappropriate interpretations. The term blastomycosis is reserved for infection (involving acute or chronic progression) with the dimorphic fungus Blastomyces dermatitides, an endemic mycosis in specific regions of the United States and Canada as well as on the African continent 24,25 , with no cases recorded in Brazil. Thus the deaths recorded as "blastomycosis" in Paraná in fact correspond to the old term "South American blastomycosis" formerly used for paracoccidioidomycosis.

In the analysis of deaths from paracoccidioidomycosis according to the revisions of the In- ternational Classification of Diseases, we observed that of the 462 deaths recorded from 1980 to 1995 (ICD-9), 66.2\% (306) were classified under the term blastomycosis (code 116.0) and 33.8\% (156) as paracoccidioidomycosis (code 116.1).

Meanwhile, from 1996 to 1998 (ICD-10), out of the total of 89 deaths, 85 (95.5\%) were coded as paracoccidioidomycosis (code B41) and 4 (4.5\%) as blastomycosis (code B40).

Analyzing the death certificates from paracoccidioidomycosis for the years 1996, 1997, and 1998 and obtained from the SES-PR, we observed that the vast majority of the physicians identified the cause of death as "blasto- 
mycosis", such that the percentage found in the historical series studied (56.2\%) would be higher if it were not for the intervention by the individuals in charge of the mortality data treatment in altering code B40 for "blastomycosis" to B41 for "paracoccidioidomycosis". Of the 89 deaths recorded during this period, only 14 death certificates $(15.7 \%)$ used the term paracoccidioidomycosis. Some death certificates had annotations by coders referring to the occurrence of blastomycosis in the United States and paracoccidioidomycosis in Brazil. Other problems were also observed, especially the lack of physician training for filling out death certificates, as well as coding errors for basic cause of death.

In dealing with mortality data, one should also evaluate the possibility of under-recording, observing the high rates of deaths resulting from lack of medical care and deaths from unknown causes. This aspect needs to be taken into consideration, since individuals involved in agricultural activities constitute the majority of patients with mycoses, predominating among those with more precarious economic conditions. In addition, although the laboratory diagnosis of paracoccidioidomycosis is easy to perform, it is relatively difficult to order in most clinics due to the lack of proper laboratory resources and personnel training to perform the exams.

Among the predominantly chronic infectious diseases, this mycosis occupied fifth place during the study period, with a mortality coefficient of 3.48, behind Chagas disease with 41.8 (6,618 deaths), tuberculosis with 29.15 (4,615 deaths), AIDS with 19.53 (3,092 deaths), and Hansen disease with 4.24 per million inhabitants (672 deaths). Paracoccidioidomycosis was ahead of diseases like cysticercosis, with a mortality coefficient of 1.93 (306 deaths), ascaridiasis, with 1.67 (264 deaths), schistosomiasis with 1.52 (240 deaths), syphilis with 1.42 (225 deaths), and malaria with 1.12 per million inhabitants (177 deaths).

Other systemic mycoses were also listed, with cryptococcosis showing a coefficient of 0.31 (49 deaths), histoplasmosis with 0.04 (6 deaths), and aspergillosis with 0.03 per million inhabitants (5 deaths).

Although paracoccidioidomycosis occupied fifth place among the predominantly chronic infectious diseases during the study period, presenting a higher mortality coefficient than such diseases as cysticercosis, schistosomiasis, leishmaniasis, and malaria, it may not be a sufficiently visible endemic due to the lack of knowledge on its epidemiology and the health system's diagnostic deficiencies, among other factors, thus hindering the application of mea- sures to prevent this mycosis, which constitutes a serious social and health problem.

During the year 2001, a group of medical professionals from the SES-PR, the Universidade Federal do Paraná (Federal University in Paraná), and the Universidade Estadual de Maringá (State University in Maringá) developed a paracoccidioidomycosis protocol, which was officially launched during the Congress on Tropical Medicine in Foz do Iguaçu on February 27, 2002. This protocol aims to standardize patient treatment for paracoccidioidomycosis in Paraná, as well as to ensure the availability of the antigen for serological reactions and provide antifungal drugs, indicating itraconazole as the currently recommended treatment of choice.

According to the protocol, the Basic Health Units should refer patients with suspected diagnosis to the Specialty Reference Center or Reference Unit, which should order a laboratory diagnosis, and in positive cases a serological examination should be performed. In addition, the following forms should be filled out: Notification of New Paracoccidioidomycosis Cases and Requisition for Special Medication.

The launching of the "Paracoccidioidomycosis Protocol" was an important step, since the natural history of this disease without specific therapeutic intervention generally evolves to death.

\section{Conclusion}

In relation to paracoccidioidomycosis mortality in the State of Paraná from 1980 to 1998; we conclude that the mean annual mortality coefficient was 3.48 per million inhabitants, with a greater prevalence in males, in the 30 to 59 year age bracket, and in rural workers.

The disease was detected in 184 (46.1\%) of the State's municipalities, highlighting Curitiba, Londrina, Toledo, Ponta Grossa, Cascavel, and Prudentópolis. The North-Central mesoregion showed the highest number of deaths from this mycosis, and the Western meso-region showed the highest mortality coefficient from paracoccidioidomycosis.

Paracoccidioidomycosis was the fifth cause of mortality among the predominantly chronic infectious and parasitic diseases, considerably higher than the mortality from other systemic mycoses like cryptococcosis and histoplasmosis. Meanwhile, $56.2 \%$ of the deaths from this disease were coded under the term blastomycosis.

For the Brazilian States as a whole, Paraná occupies second place for deaths from this mycosis, and among the States of the South and Southeast it has the highest mortality coefficient. 


\section{Resumo}

Foi conduzido um estudo de mortalidade por paracoccidioidomicose no Estado do Paraná, Brasil, no período de 1980 a 1998, utilizando-se como fonte de dados os registros de óbitos do Sistema de Informação sobre Mortalidade e a população estimada pelo Instituto Brasileiro de Geografia e Estatística. Para classificação dos óbitos, empregou-se a CID-9 para os anos de 1980 a 1995 e a CID-10 para os anos mais recentes. Nesse período, no Paraná, ocorreram 551 óbitos por paracoccidioidomicose, com prevalência do sexo masculino, na faixa etária compreendida ente 30 a 59 anos. A taxa de mortalidade média anual foi de 3,48 por milhão de habitantes, demonstrando estabilidade no período de estudo. Destacou-se como a quinta causa de mortalidade entre as doenças infecciosas e parasitárias redominantemente crônicas, apresentando a mais alta taxa de mortalidade entre as micoses sistêmicas. Foi observada em 184 municípios, verificando-se, no estudo por mesorregiões, maior número de óbitos no Norte Central e o maior coeficiente de mortalidade no Oeste do Paraná.

Paracoccidioidomicose; Mortalidade; Micose

\section{Contributors}

The first draft of the article was written by J. I. M. Bittencourt, with collaboration and orientation from R. M. Oliveira in the original design, construction of the tabular plan, and elaboration of calculations, graphs, and tables as well as revision of the text. The collaboration by Z. F. Coutinho took place from the design phase through the article draft, literature review, and final revision of the text.

\section{References}

1. Franco M, Bagagli E, Scapolio S, Lacaz CS. A critical analysis of isolation of Paracoccidioides brasiliensis from soil. Med Mycol 2000; 38:185-91.

2. Mendes-Giannini MJS, Melhem MSC. Infecções fúngicas. In: Ferreira AW, Ávila SLM, organizadores. Diagnóstico laboratorial das principais doenças infecciosas e auto-imunes. Rio de Janeiro: Guanabara Koogan; 1996. p. 255-7.

3. Tendrich M, Wanke B, Del Negro G, Wajchenberg BL. Adrenocortical involvement. In: Franco M, Lacaz CS, Restrepo-Moreno A, Del Negro G, editors. Paracoccidioidomycosis. Boca Raton: CRC Press; 1994. p. 303-12.

4. Governo do Paraná. Protocolo de paracoccidioidomicose. Curitiba: Secretaria de Estado da Saúde do Paraná; 2002.

5. Gonçalves AJR, Somogy LA, Braga MP, Pedrosa MC, Carvalho FG, Vieira ARM, et al. Paracoccidioidomicose (blastomicose sul-americana): experiência de um hospital geral. Arq Bras Med 1984; 58 Suppl 4:237-43.

6. Mcewen JG, Garcia AM, Ortiz BL, Botero S, Restrepo A. In search of the natural habitat of Paracoccidioides brasiliensis. Arch Med Res 1995; 26 Suppl 3:305-6.

7. Restrepo A, Mcewen JG, Castañeda E. The habitat of Paracoccidioides brasiliensis: how far from solving the riddle? Med Mycol 2001; 39:233-41.

8. Coutinho ZF. Mortalidade por paracoccidioidomicose no Brasil. 1980/1995 (Estudo descritivo) [Dissertação de Mestrado]. São Paulo: Escola Paulista de Medicina, Universidade Federal de São Paulo; 1999.

9. Coutinho ZF, Silva D, Lazéra M, Petri V, Oliveira RM, Sabroza PC, et al. Paracoccidioidomycosis mortality in Brazil, 1980/1995. Cad Saúde Pública 2002; 18:1441-54.

10. Valle ACF, Coimbra Jr. CEA, Bornay-Llinares FI, Monteiro PCF, Guimarães MRC. Paracoccidioidomicose entre o grupo indígena Suruí de Rondônia, Amazônia, Brasil. Registro de caso. Rev Inst Med Trop São Paulo 1991; 33 Suppl 5:407-11.

11. Martins RM, Marques JLO, Garcez ICS, Mello CFC, Barbosa BG, Guimarães WD, et al. Paracoccidioidomicose. Relato de caso em criança de três anos de idade com forma disseminada. J Pediatr 1986; 61:319-22.

12. Londero AT, Ramos CD. Paracoccidioidomicose. Estudo clínico e micológico de 260 casos observados no interior do Estado do Rio Grande do Sul. J Pneumol 1990; 16 Suppl 3:129-32.

13. Londero AT, Melo IS. Paracoccidioidomicose. Curso - doenças infecto-parasitárias. J Bras Med 1988; 55 Suppl 3:96-111.

14. Blotta MHSL, Mamoni RL, Oliveira SJ, Nouer SA, Papaiordanou PMO, Goveia A, et al. Endemic regions of paracoccidioidomycosis in Brazil: a clinical and epidemiologic study of 584 cases in the southeast region. Am J Trop Med Hyg 1999; 61 Suppl 3:390-4.

15. Marques SA, Franco MF, Mendes RP, Silva NCA, Baccili C, Curcelli ED, et al. Aspectos epidemiológicos da paracoccidioidomicose na área endêmica de Botucatu (São Paulo - Brasil). Rev Inst Med Trop São Paulo 1983; 25 Suppl 2:87-92. 
16. Mesquita FCL, Miranda MFR, Bichara CNC, Magalhães RAF. Paracaccidioidomicose. In: Leão RNQ, coordenador. Doenças infecciosas e parasitárias. Enfoque amazônico. Belém: Editora Cejup; 1997. p. 767-81.

17. Telles Filho FQ, Brandão HE, Boscardini R, Macedo E, Barros JA, Marquetti JL, et al. Alguns aspectos clínicos e epidemiológicos da paracoccidioidomicose no Estado do Paraná. Rev Soc Bras Med Trop 1986; 19:93.

18. Borelli D. Concepto de reservárea. La reducida reservárea de la paracoccidioidomicosis. Dermatol Venez 1964; 4:71-7.

19. Restrepo A. The ecology of Paracoccidioides brasiliensis: a puzzle still unsolved. Sabouraudia 1985; 23:323-34.

20. Calle D, Rosero DS, Orozco LC, Camargo D, Castaneda E, Restrepo A. Paracoccidioidomycosis in Colombia: an ecological study. Epidemiol Infect 2001; 126:309-15.
21. Silva-Vergara ML, Martinez R, Chadu A, Madeira, M, Freitas-Silva G, Leite-Maffei CM. Isolation of a Paracoccidioides brasiliensis strain of a coffee plantation in Ibiá, State of Minas Gerais, Brazil. Med Mycol 1998; 36:37-42.

22. Kleinke MLU, Deschamps MV, Moura R. Movimento migratório no Paraná (1986-91 e 1991-96): origens distintas e destinos convergentes. Revista Paranaense de Desenvolvimento 1999; 95:27-50.

23. Fava SC. Contribuição à epidemiologia da paracoccidioidomicose no Estado de São Paulo - Brasil [Dissertação de Mestrado]. São Paulo: Escola Paulista de Medicina, Universidade Federal de São Paulo; 1984.

24. Marques SA. Paracoccidioidomicose. An Bras Dermatol 1998; 73 Suppl 5:455-69.

25. Sidrim JJC, Moreira JLB. Fundamentos clínicos e laboratoriais da micologia médica. Rio de Janeiro: Guanabara Koogan; 1999.

Submitted on 14/Jun/2004

Final version resubmitted on 18/Nov/2004 Approved on 24/Nov/2004 